\title{
IDENTIFICATION AND CHARACTERIZATION OF 3.8 min ${ }^{134}$ mI
}

\author{
C.D. CORYELL ${ }^{\dagger}$, H.N. ERTEN ${ }^{\dagger \dagger}$, P. K. HOPKE ${ }^{\dagger \dagger}$ and W.B. WALTERS ${ }^{\S}$ \\ Arthur A. Noyes Nuclear Chemistry Center ${ }^{\S \$}$, Massachusetts Institute of Technology, \\ Cambridge, Massachusetts, USA \\ and \\ R. DAMS ${ }^{\S \S}$ and H.C. GRIFFIN \\ University of Michigan, Ann Arbor, Michigan, USA
}

Received 30 July 1971

\begin{abstract}
The $\gamma$-ray spectra of iodine fractions rapidly separated from the products of slow neutron fission of ${ }^{235} \mathrm{U}$ were studied. A $3.8 \pm 0.2$ min species was found and was identified as ${ }^{134{ }^{211} \mathrm{I}}$ from observations of corresponding growth in the intensities of the prominent 847 and $884 \mathrm{keV} \gamma$-rays of $53 \mathrm{~min}{ }^{134} \mathrm{I}$. This isomer is analogous to the $2.9 \mathrm{~h}$ isomer ${ }^{134 \mathrm{~m}} \mathrm{Cs}$ and decays by the sequence ${ }^{134 \mathrm{~m}} \mathrm{I}\left(J^{n}=8^{-}\right) \stackrel{\mathrm{E}^{3}}{\longrightarrow}\left(J^{\pi}=5^{+}\right) \stackrel{\mathrm{M} 1}{\longrightarrow}{ }^{134} \mathrm{I}\left(J^{\pi}=4^{+}\right)$by transitions of $271.9 \pm 0.2 \mathrm{keV}\left(t_{\frac{1}{2}}=3.8 \mathrm{~min}\right.$; $\left.\alpha_{\mathrm{K}}<0.3\right)$ and $44.4 \pm 0.1 \mathrm{keV}\left(t_{\frac{1}{2}}<10 \mathrm{~ns} ; \alpha_{\mathrm{K}}<7\right)$, respectively. For a $316 \mathrm{keV}$ cross-over $\gamma$-ray an upper limit of $1 \%$ was obtained, and is near the intensity predicted by M4 systematics. A low-intensity $\gamma$-ray of $234.3 \pm 0.5 \mathrm{keV}$ was found. This $\gamma$-ray is interpreted as evidence for $\beta$-decay ( $2 \%$ ) of the isomer, possibly to the $0.29 \mathrm{sec} 7^{-}$isomeric level in ${ }^{134} \mathrm{Xe}$.
\end{abstract} coinc.; deduced $\log f t{ }^{134} \mathrm{I}$ deduced levels, $J, \pi . \mathrm{Ge}(\mathrm{Li}), \mathrm{NaI}(\mathrm{TI})$, liquid scintillation detectors.

\section{Introduction}

The short-lived halogen fission products have been studied by many workers, including Sugarman ${ }^{1}$ ), Perlow and Stehney ${ }^{2}$ ), Johnson and O'Kelley ${ }^{3}$ ), Denschlag and Gordus ${ }^{4}$ ), and Lundán and Siivola ${ }^{5}$ ). The decay of $53 \mathrm{~min}{ }^{134} \mathrm{I}$ in particular has been widely studied ${ }^{6-10}$ ). The ${ }^{134} I$ sources used in those studies were obtained by milking iodine from fission-product $42 \mathrm{~min}{ }^{134} \mathrm{Te}$. This method of preparation would not yield an appreciable amount of any high-spin isomer as the $\beta$-decay of $0^{+}$ ${ }^{134} \mathrm{Te}$ is not known to populate even the $5^{+}$level at $44 \mathrm{keV}$ discovered in this study.

In the course of studies of the $\gamma$-ray spectra of short-lived fission product iodine activities, evidence was obtained ${ }^{11}$ ) for a $3.8 \mathrm{~min}$ isomer of ${ }^{134}$ I. These studies revealed that the predominant mode of decay leads to $53 \mathrm{~min}{ }^{134} \mathrm{I}$ and involves $\gamma$-rays of 272

$\dagger$ Deceased, January 7, 1971.

${ }^{\dagger}$ On leave from Middle East Technical University, Ankara, Turkey.

$t^{\dagger \dagger}$ Present address: Department of Chemistry, State University College, Fredonia, New York 14063.

$\S$ Present address: Department of Chemistry, University of Maryland, College Park, Maryland 20742.

$\$ 5$ Supported in part by Atomic Energy Commission under Contract $\Lambda \mathrm{T}(30-1)-905$.

$\$$ Present address: University of Gent, Gent, Belgium. 
and $44 \mathrm{keV}$ as well as iodine $\mathrm{K}$ X-rays. It appears that failure to identify this isomer in the previous studies of $\gamma$-ray spectra of short-lived isotopes of iodine resulted from the assumption that the $273 \mathrm{keV} \gamma$-ray is associated with the decay of $3.9 \mathrm{~min}{ }^{137} \mathrm{Xe}$. However, Holm ${ }^{12}$ ) has made a detailed study of the decay of ${ }^{137} \mathrm{Xe}$ and did not find a $\gamma$-ray near $272 \mathrm{keV}$, even in low intensity.

Delucci et al. ${ }^{13}$ ) have suggested that the non-Gaussian charge dispersion of the $A=134$ isobars produced in the fission of ${ }^{235} \mathrm{U}$ could be explained by the existence of isomers in ${ }^{134} \mathrm{Sb}$ or ${ }^{134} \mathrm{I}$ if the postulated isomer decayed largely by $\beta^{-}$decay. Our initial studies of ${ }^{134 \mathrm{~m} I}$ and the results of independent work by Carraz, Blachot, Monnand, and Moussa ${ }^{14}$ ) failed to reveal a $\beta^{-}$branch in the decay of the isomer. Therefore we attempted to obtain more detailed information on this decay scheme, with particular attention to the possibility of $\beta$-decay and the relative independent yields in fission of the ground and metastable states.

Iodine samples rapidly separated from the thermal-neutron fission products of ${ }^{235} \mathrm{U}$ contain a mixture of iodine nucleides and their daughter nucleides. The pertinent species are indicated in fig. 1. Iodine isotopes with mass numbers below 134 have long half-lives and are not observed because they are not formed directly in fission in high yield. Those with mass numbers above 137 have very short half-lives. The main species observed are short-lived activities with half-lives of $45 \mathrm{sec}, 83 \mathrm{sec}$, $3.8 \mathrm{~min}\left({ }^{134 \mathrm{~m}} \mathrm{I}\right)$, and $53 \mathrm{~min}\left({ }^{134 \mathrm{~g}} \mathrm{I}\right)$. The $83 \mathrm{sec}$ species is ${ }^{136} \mathrm{I}$, studied by Johnson and $\mathrm{O}^{\prime}$ Kelley ${ }^{3}$ ), and by Lundan and Siivola ${ }^{5}$ ). The $45 \mathrm{sec}$ species has generally been characterized as an isomer of $\left.{ }^{136} \mathrm{I}\left[\mathrm{ref} .{ }^{5}\right)\right]$. Initially ${ }^{11}$ ) we had inferred that this species was a high-spin isomer with mass number greater than 135 , possibly an odd-mass I isomer. We subsequently confirmed ${ }^{15}$ ) the Lundan and Siivola assignment as an isomer of ${ }^{136} \mathrm{I}$.

If we take the absence of ${ }^{134} \mathrm{~m}$ I among the products of the decay of ${ }^{134} \mathrm{Te}$ as evidence for relatively high spin for this isomer, and if we assume the long half-life of the isomer implies a spin at least 3 units higher or lower than the $4^{+}$ground state of ${ }^{134} \mathrm{I}$, we conclude that the isomer has spin $\geqq 7$. Therefore $\beta$-transitions of observable intensity to ${ }^{134} \mathrm{Xe}$ would be limited to transitions to states with spins $\geqq 5$. Because of the large $\beta$-decay energy of ${ }^{134 \mathrm{~m}} \mathrm{I}(4.15 \mathrm{MeV})$, many levels of high spin may be accessible to $\beta$-decay of the isomer, but few high-spin states are known. However, a likely candidate for such a state is the $7^{-}$two-neutron isomer identified by Winn and Clark ${ }^{16}$ ). This isomer is reported to decay by a cascade of $\gamma$-rays, the first of which has an energy of $233 \pm 1.5 \mathrm{keV}$, and is not populated in the decay of ${ }^{134 \mathrm{gI}}$ [ref. $\left.{ }^{10}\right)$ ]. Therefore we have sought a $\gamma$-ray of about this energy in the decay of ${ }^{134 \mathrm{~m}} \mathrm{I}$.

\section{Experimental methods and results}

\subsection{SOURCE PREPARATION}

The I samples were isolated rapidly from the products of slow-neutron fission of ${ }^{235} \mathrm{U}$. Separations employing distillation and solvent extraction were used. The 
distillation method was based on the procedure of Op de Beeck and Walters ${ }^{17}$ ). The solvent extraction method used the nitrite oxidation and sulfite reduction steps of Campbell and Brady ${ }^{18}$ ). Although some contamination was found in samples prepared by the distillation method, no contaminants were found in samples prepared by solvent extraction followed by precipitation and filtration of AgI. Final samples consisted of aqueous solutions (for study of $\gamma$-rays of $200-400 \mathrm{keV}$ ), extracts of $I_{2}$ in toluene based scintillator ( $\beta-\gamma$ anticoincidence studies), or filtered precipitates of AgI or $\mathrm{AgBr}(\mathrm{I})$. The $\mathrm{AgBr}(\mathrm{I})$ samples contained only small amounts $(<500 \mu \mathrm{g})$ of I to permit the study of iodine $\mathrm{K} \mathrm{X}$-rays without interference from fluorescence of the bulk material.

For measurements of low-intensity transitions in the decay of the isomer, the timings of the various steps in the separations were chosen to enhance the purity of the $3.8 \mathrm{~min}{ }^{134 \mathrm{~m}}$ I relative to the other iodine activities and xenon daughters. The pertinent genetic relations are given in fig. 1 . In order to minimize the activity of $53 \mathrm{~min}^{134} \mathrm{I}$,

SOME IOUINE Fission Products

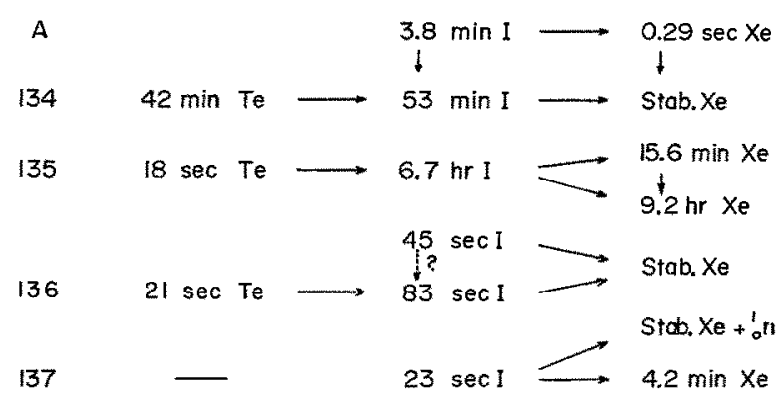

Fig. 1. Some iodine fission products observed in rapidly separated iodine samples.

the initial isolation of I from fission products was made soon after a short irradiation, typically within $1 \mathrm{~min}$ after a $20 \mathrm{sec}$ irradiation. The precipitation and filtration steps were delayed $\left(\approx 4 \mathrm{~min}\right.$ after irradiation) to minimize the amount of $4.2 \mathrm{~min}{ }^{137} \mathrm{Xe}$ in the final sample. In order to determine contributions from species other than ${ }^{134} \mathrm{~m}$, the timings were varied in a variety of additional measurements.

\subsection{SINGLE DETECTOR MEASUREMENTS}

Evidence for an isomeric state in ${ }^{134} \mathrm{I}$ was obtained from the time dependence of the intensity of the major $\gamma$-rays of $53 \mathrm{~min}{ }^{134} \mathrm{I}$ in samples of I isolated from a fresh mixture of fission products. An example of the growth and decay curve observed for the $847 \mathrm{keV} \gamma$-ray is shown in fig. 2 . The data were obtained from a series of $\gamma$-ray spectra observed with a $26 \mathrm{~cm}^{3} \mathrm{Ge}(\mathrm{Li})$ detector. The growth portion corresponds to 


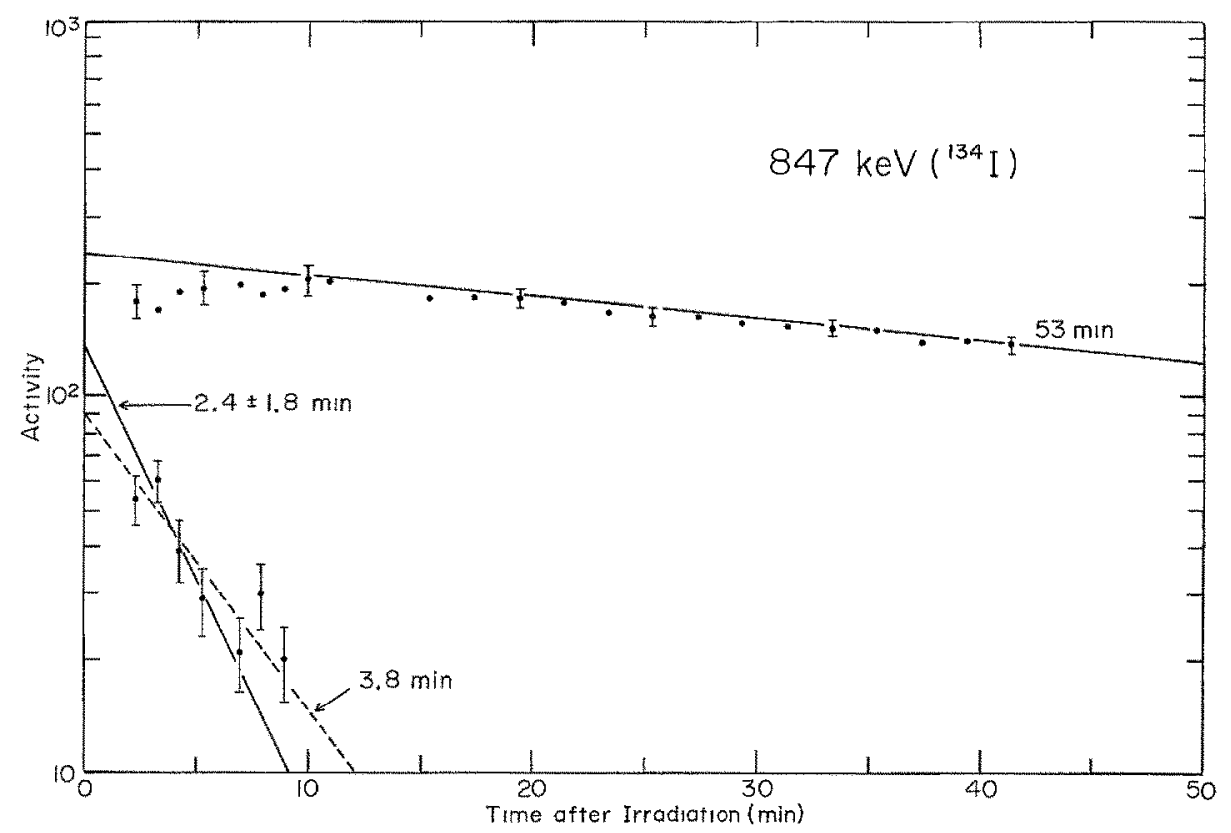

Fig. 2. The growth and decay curve of the $847 \mathrm{keV} \gamma$-ray belonging to the decay of ${ }^{134} \mathrm{I}$ isomers, observed with a $26 \mathrm{~cm}^{3} \mathrm{Ge}(\mathrm{Li})$ detector.

a $2.4 \pm 1.8 \mathrm{~min}$ precursor. The large uncertainty in the half-life results from timedependent pile-up losses from the spectral peaks and the relatively small intensity of the growth component. However this half-life is, within experimental uncertainties, in agreement with the $3.8 \pm 0.2 \mathrm{~min}$ half-lives (see fig. 3) observed for iodine $\mathrm{K}$ X-rays and $\gamma$-rays of 44 and $272 \mathrm{keV}$ observed in similar spectra. These data suggest the isomer decays by an isomeric transition of 44 or $272 \mathrm{keV}$, or possibly by a highly converted transition which was not detected.

Confirmation of the identification of the $3.8 \mathrm{~min}$ activity as an isotope of I was obtained by chemical means. When xenon was extracted into cold $\mathrm{CCl}_{4}$ from an aqueous sulfite solution of fission product $\mathrm{I}$, only ${ }^{137} \mathrm{Xe}$ and small amounts of ${ }^{135} \mathrm{~m} \mathrm{Xe}$ were observed. Performing a second purification cycle on the isolated I fraction failed to change the ratios of the activities of the $3.8 \mathrm{~min}$ component and ${ }^{134} \mathrm{~g}$. The $3.8 \mathrm{~min}$ component could not be detected in the I fraction isolated from fission products $30 \mathrm{~min}$ after fission. This last result indicates that this component is not produced to an appreciable extent in the decay of a Te isotope with mass number less than 135 .

During the study of ${ }^{134 \mathrm{~m}}$ I several different detectors were used. These detectors included $\mathrm{Ge}(\mathrm{Li})$ detectors with sizes of from 0.4 to $45 \mathrm{~cm}^{3}$ and a $\mathrm{Si}(\mathrm{Li})$ detector. The most useful spectra were obtained with a $1 \mathrm{~cm}^{3}$ high-resolution $\mathrm{Ge}(\mathrm{Li})$ detector. A typical spectrum obtained with this detector is given in fig. 4 . All of the features of 


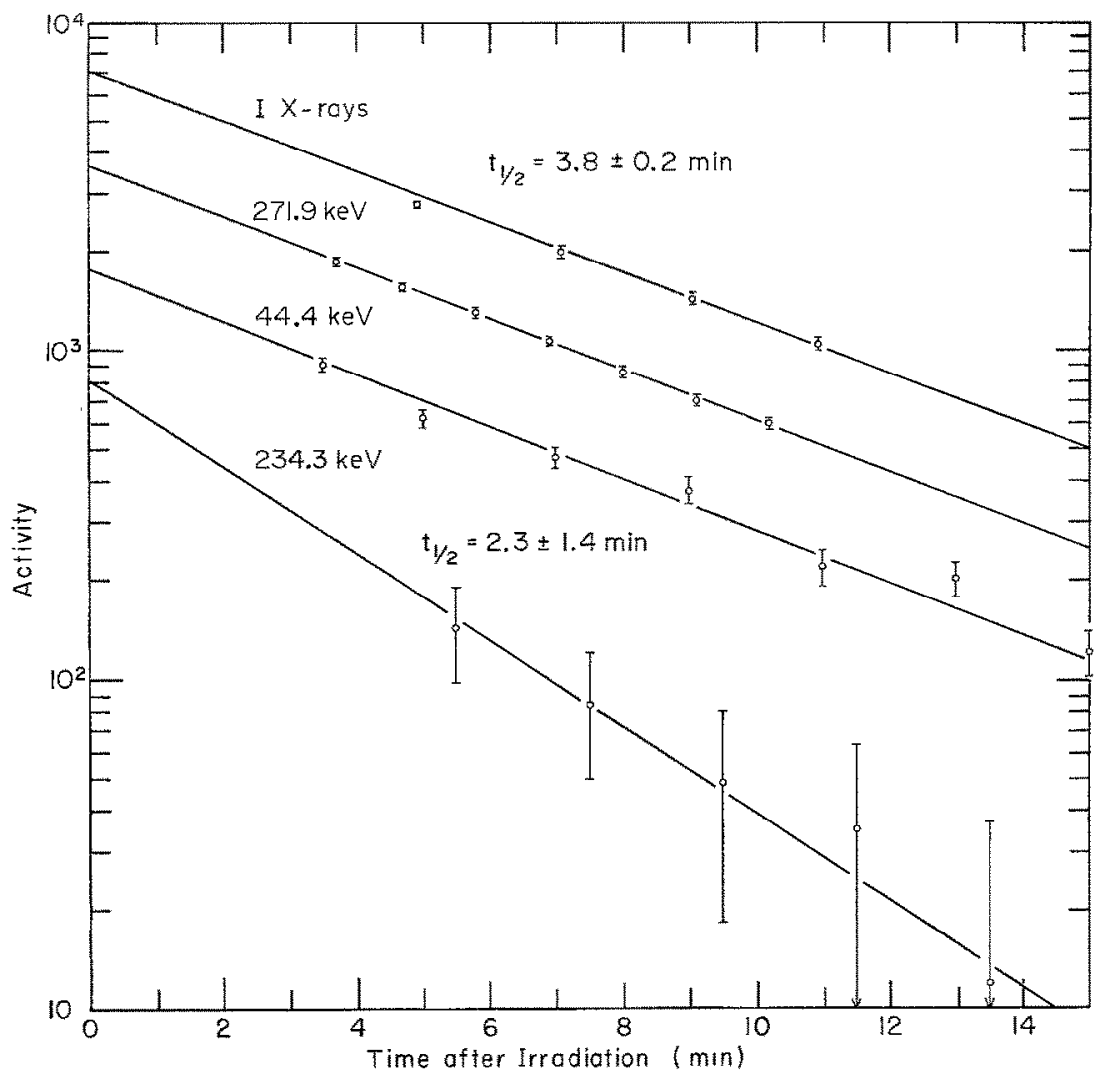

Fig. 3. Decay curves for iodine X-rays, $44.4,271.9$ and $234.3 \mathrm{keV} \gamma$-rays observed with 0.4 and $26 \mathrm{~cm}^{3} \mathrm{Ge}(\mathrm{Li})$ detectors.

these spectra can be identified with isotopes of $I$ or their Xe daughters. In addition to the prominent radiations of ${ }^{134 \mathrm{~m}} \mathrm{I}$, namely the iodine $\mathrm{K} X$-rays and $\gamma$-rays of 44.4 and $271.9 \mathrm{keV}$, a low-intensity $\gamma$-ray of $234.3 \pm 0.5 \mathrm{keV}$ can be seen. The intensities of this $\gamma$-ray in several spectra of this type indicate that the parent nucleide has a half-life of between 2.5 and $5 \mathrm{~min}$. However the uncertainty in the half-life indicated the need for additional data in order to assign this transition to the decay of ${ }^{134 \mathrm{~m}} \mathrm{I}$. The intensity of the $234 \mathrm{keV} \gamma$-ray was obtained by analyzing the broad peak at about $235 \mathrm{keV}$ as a doublet consisting of a $3.8 \mathrm{~min} 234.3 \mathrm{keV}$ component and a $53 \mathrm{~min} 235.3 \mathrm{keV}$ component. This intensity was found to be $2.0 \pm 0.8$ relative to 100 for the $271.9 \mathrm{keV} \gamma$-ray; this result is not sensitive to the assumed energies.

The time dependence of the intensities of the iodine $\mathrm{K} \mathrm{X}$-rays appeared to follow a pure $3.8 \mathrm{~min}$ half-life. No evidence for $45 \mathrm{sec}$ or $85 \mathrm{sec}$ components was obtained. The intensities of the Xe X-rays were much more complex, although a detailed analysis was not made. In spectra obtained within two min of the end of the irradiation, the 

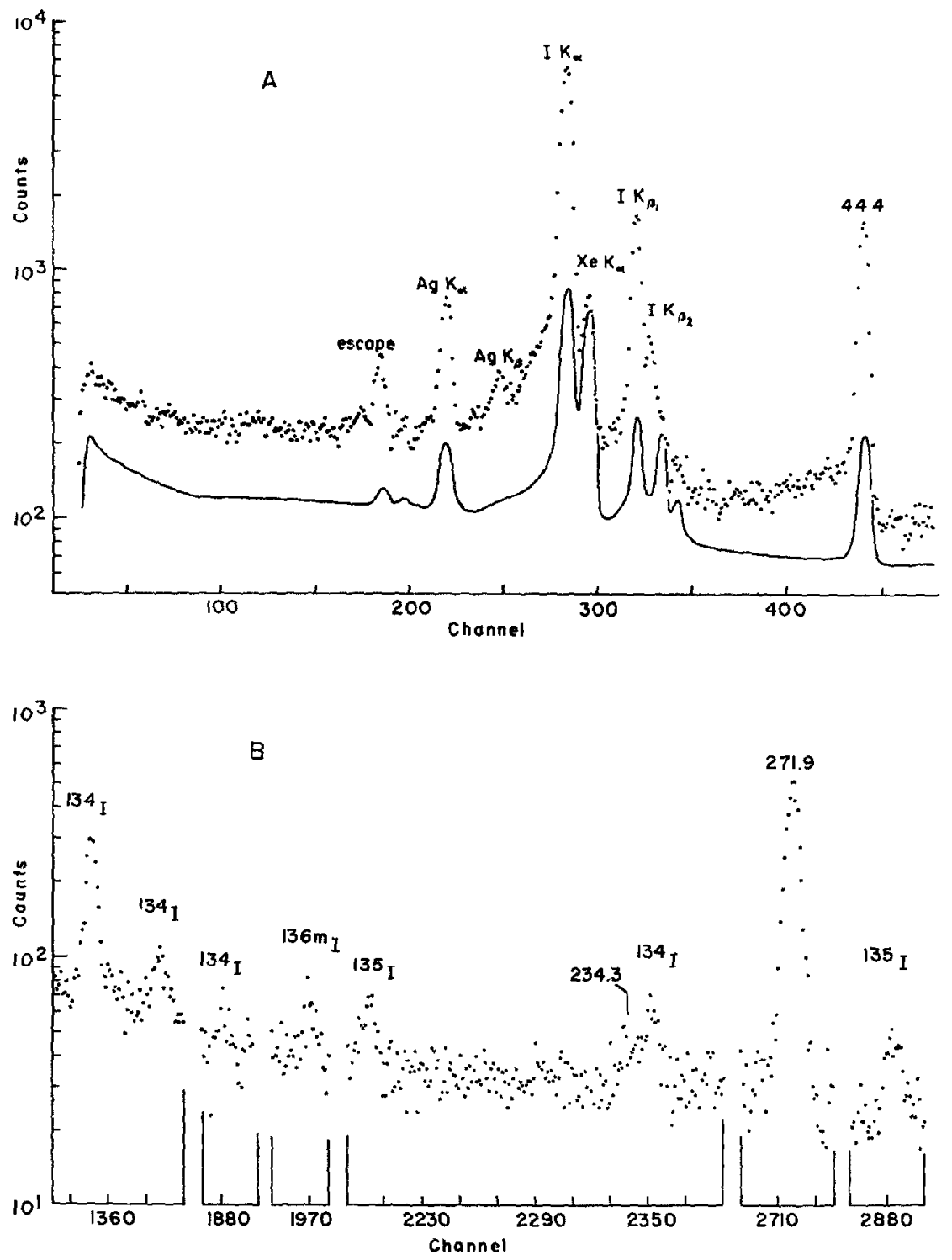

Fig. 4. High-resolution 7 -ray spectrum. The points correspond to the spectrum obtained between 6.8 and $13.8 \mathrm{~min}$ after the end of irradiation. Fot the low-energy region (A) the solid curve is the spectrum obtained $12 \mathrm{~min}$ later. Portions of the spectrum corresponding to all of the peaks discernible in the high-energy region are given in $\mathrm{B}$.

Xe X-ray peak was nearly as high as the I peak, implying that there is considerable conversion in ${ }^{136} \mathrm{Xe}$ following the decay of ${ }^{136} \mathrm{~m}_{\mathrm{I}}$ or ${ }^{136 \mathrm{~g}} \mathrm{I}$. 


\subsection{THE $\gamma-\gamma$ COINCIDENCE MEASUREMENTS}

The genetic relation between the 44.4 and $271.9 \mathrm{keV} \gamma$-rays was established by coincidence measurements and inferences based on conversion coefficients. In the coincidence measurements a $5 \mathrm{~cm} \times 5 \mathrm{~cm} \mathrm{NaI}(\mathrm{Tl})$ detector was used to detect lowenergy photons (primarily I K X-rays), and a $\mathrm{Ge}(\mathrm{Li})$ detector was used for the $271.9 \mathrm{keV} \gamma$-ray. The spectrum of radiations coincident with the $271.9 \mathrm{keV} \gamma$-ray shows features which are consistent with iodine $\mathrm{K} \mathrm{X-rays} \mathrm{and} \mathrm{an} \mathrm{incompletely} \mathrm{re-}$ solved $44 \mathrm{keV} \gamma$-ray. In this spectrum the relative intensities of the $\mathrm{X}$-rays and the $44 \mathrm{keV} \gamma$-ray appear to be about the same as in the singles spectra. The spectrum coincident with the peak identified as iodine $\mathrm{K} \mathrm{X}$-rays shows the $271.9 \mathrm{keV} \gamma$-ray as the major component for energies above the $100 \mathrm{keV}$ cut-off in that channel. These results indicate that the predominant mode of decay involves a two-step cascade with transitions of 44.4 and $271.9 \mathrm{keV}$. However the order is not determined.

Several attempts were made to measure the half-life of the intermediate state in the cascade. Such a measurement would also determine the order of the cascade. One method employed Naton plastic detectors and fast electronics. No energy selection, other that discriminators, was used. The time spectra were dominated by prompt coincidences $(\Delta t \approx 1 \mathrm{nsec})$ which could not be assigned to ${ }^{134 \mathrm{~m}} \mathrm{I}$. Other measurements employed $\mathrm{NaI}(\mathrm{Tl})$ detectors and 10-stage photomultipliers with poor timing characteristics. In these measurements pulse-height selection was used, and the time spectra from a time-to-amplitude converter showed variation of intensity with time which corresponds to $3.8 \mathrm{~min}^{134 \mathrm{~m}} \mathrm{I}$. However the time resolution $(\approx 30 \mathrm{nsec})$ was so poor and statistical uncertainties so large that no clear deviation from the prompt calibration curve could be detected. These measurements indicate that the half life of the $44.4 \mathrm{keV}$ level is less than $10 \mathrm{nsec}$.

\subsection{THE $\beta-\gamma$ ANTICOINCIDENCE MEASUREMENTS}

The main interference with detection of 234 or $316 \mathrm{keV} \gamma$-rays which might be emitted in the decay of ${ }^{134 \mathrm{~m}} \mathrm{I}$ was due to contributions of ${ }^{134 \mathrm{~g}} \mathrm{I}$ and ${ }^{135} \mathrm{I}$ to the spectra. If the $234 \mathrm{keV} \gamma$-ray results from decay of the $0.29 \mathrm{sec} 7^{-}$level in ${ }^{134} \mathrm{Xe}$ and the $316 \mathrm{keV}$ $\gamma$-ray is the crossover transition in isomeric decay of ${ }^{134} \mathrm{~m} \mathrm{I}$, neither of these $\gamma$-rays will be in prompt coincidence with $\beta$-rays. The $\beta$ - $\gamma$ anticoincidence measurements were performed as follows. The I was isolated by extraction of $\mathrm{I}_{2}$ into toluene, by washing, and by extraction of $\mathrm{I}^{-}$into aqueous sulfite solution. The I was reoxidized and extracted into $15 \mathrm{ml}$ of toluene-based scintillator solution. The loaded scintillator was transferred to a glass vial optically coupled to a $4 \mathrm{~cm}$ photomultiplier. Gamma rays were detected in a $35 \mathrm{~cm}^{3} \mathrm{Ge}(\mathrm{Li})$ detector, the pulses from which were controlled by a conventional anticoincidence circuit and linear gate. The anticoincidence efficiency was a function of count rate because of the dead-time of the anticoincidence circuit. However in favourable cases the contributions from $\gamma$-rays in prompt coincidence with $\beta$-rays could be reduced to about $5 \%$ their intensity in singles spectra. 
$\Lambda$ spectrum obtained in the anticoincidence configuration is given in fig. 5 . Although the resolution of the detector was insufficient to resolve the $234 \mathrm{keV} \gamma$-ray of ${ }^{134 \mathrm{~m} I}$ from the $235.3 \mathrm{keV} \gamma$-ray of ${ }^{134 \mathrm{~g}} \mathrm{I}$, the presence of the $234 \mathrm{keV} \gamma$-ray is evident in the short half-life of the main component at $234 \mathrm{keV}$ and the shift in energy of this

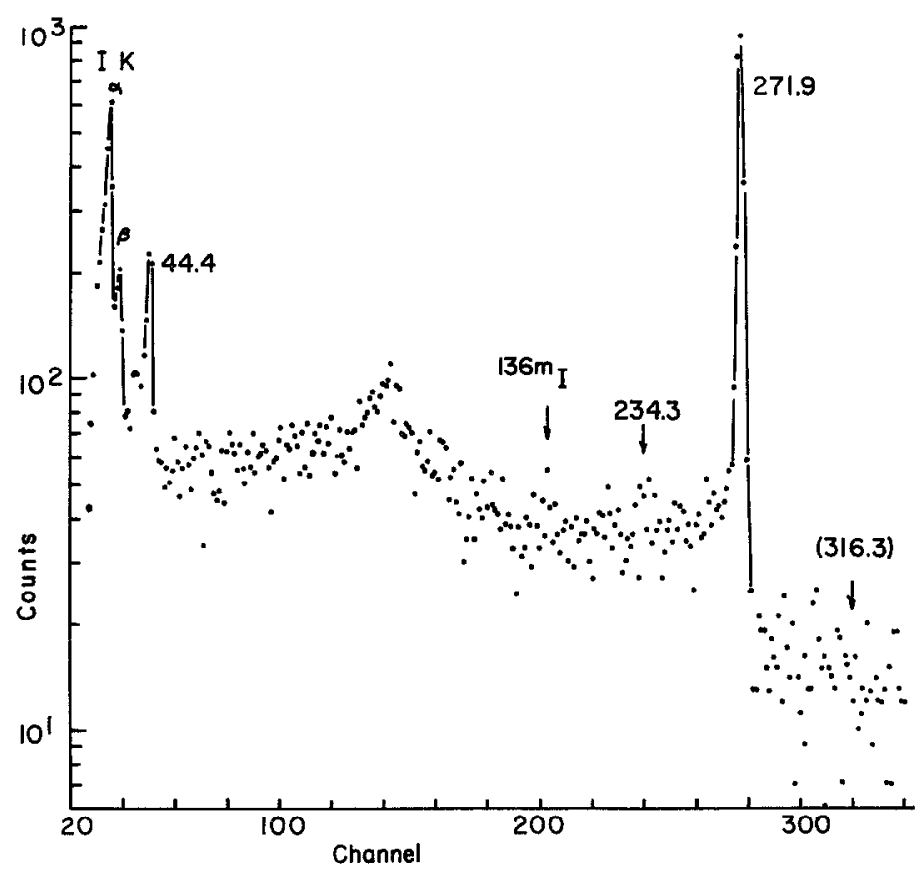

Fig. 5. Beta-anticoincidence $\gamma$-ray spectrum. The counting interval was 8 to $13 \mathrm{~min}$ after irradiation. Although no evidence for a $316.3 \mathrm{keV}$ cross-over was found, the position at which it would be found is indicated.

peak from about $234 \mathrm{keV}$ for early counts to $235 \mathrm{keV}$ when the ${ }^{134 \mathrm{~m}} \mathrm{I}$ was gone. An analysis of the intensity of the $3.8 \mathrm{~min}$ component relative to the intensity of the $272 \mathrm{keV} \gamma$-ray yielded a ratio of $0.010 \pm 0.004$. This ratio is lower than the ratio of $\gamma$-ray intensities observed in singles spectra because of the appreciable detection efficiency for the 847 and $884 \mathrm{keV} \gamma$-rays in the liquid scintillator. The probability that one or both would be detected. was estimated from Compton cross sections and found to be between 0.4 and 0.6 . Therefore the true ratio of $\gamma$-ray intensities is $0.02 \pm$ 0.01 , in agreement with the intensity determined from singles spectra. In particular the enhancement of the detection efficiency, relative to $\gamma$-rays of ${ }^{134} \mathrm{~g} I$, in the anticoincidence configuration supports the assignment as a delayed transition in ${ }^{134} \mathrm{Xe}$. No evidence for the $316 \mathrm{keV} \gamma$-ray could be obtained. The upper limit of $1 \%$ (relative to the $271.9 \mathrm{keV} \gamma$-ray) obtained from these spectra is about the same as the limit obtained from singles spectra. 


\subsection{CONSTRUCTION OF THE DECAY SCHEME}

The energies and intensities of the radiations of ${ }^{134} \mathrm{~m} I$ are summarized in columns 1 and 2 of table 1 . The energies were determined by comparison with $\gamma$-ray standards in composite spectra of ${ }^{134 \mathrm{~m}} \mathrm{I}$ and standards. The relative intensities of the major radiations were obtained primarily from spectra observed with the high resolution detectors suitable for clear resolution of the low-energy radiations. The intensity of the $234 \mathrm{keV} \gamma$-ray was obtained from singles measurements with the high-resolution detector and from the $\beta-\gamma$ anticoincidence measurements. The upper limit for the $316 \mathrm{keV}$ crossover transition was obtained from anticoincidence measurements and from singles measurements with large $\mathrm{Ge}(\mathrm{Li})$ detectors.

TABLE 1

The electromagnetic radiations from ${ }^{134 \mathrm{~m}}$ I

\begin{tabular}{cccc}
\hline $\begin{array}{c}\text { Energy } \\
(\mathrm{keV})\end{array}$ & $\begin{array}{c}\text { Relative } \\
\gamma \text {-ray intensity }\end{array}$ & $\begin{array}{c}\text { Assumed } \\
\text { conversion } \\
\text { coefficient }\end{array}$ & $\begin{array}{c}\text { Relative } \\
\text { transition } \\
\text { intensity }\end{array}$ \\
\hline iodine K X-rays & $114 \pm 10$ & 0.86 & $133 \pm 12$ \\
& $13 \pm 1$ & (K fluorescence yield) & \\
$44.4 \pm 0.2$ & $2 \pm 1$ & 7.90 & $116 \pm 8$ \\
$234.3 \pm 0.5$ & 100 & 0.46 & $2.9 \pm 1$ \\
$271.9 \pm 0.3$ & $<0.6$ & 0.23 & 123 \\
$316.3 \pm 1$ & & 1.95 & $<1.8$ \\
\hline
\end{tabular}

The $\gamma-\gamma$ coincidence measurements indicate that the predominant mode of decay of the isomer involves a cascade of transitions of 44.4 and $271.9 \mathrm{keV}$. The experiments do not specify which transition is the slow $(3.8 \mathrm{~min})$ step. The ratio of intensities of iodine $\mathrm{K} \mathrm{X}$-rays and the $44.4 \mathrm{keV} \gamma$-ray indicate that the $\mathrm{K}$ conversion coefficient of the $44.4 \mathrm{keV}$ transition is no more than about 8, which limits the transition to E1, M1 or E2. For any of these choices, a half-life of 3.8 min would be exceedingly long. The limits on the conversion of the $271.9 \mathrm{keV} \gamma$-ray, if the strong coincidence between this $\gamma$-ray and $\mathrm{K} \mathrm{X}$-rays is taken to imply that only a small portion of the X-rays arise from conversion of this $\gamma$-ray, restrict this transition to E3 or lower multipolarities. Although the required hindrance of the $271.9 \mathrm{keV} \gamma$-ray must be about $10^{5}$ if this is the isomeric transition, this hindrance is about the same as that for the E 3 transition in ${ }^{134 \mathrm{~m}} \mathrm{Cs}$, which appears to be analogous to ${ }^{134 \mathrm{~m}} \mathrm{I}$. If the $271.9 \mathrm{keV}$ transition is $\mathrm{E} 3$, the most likely assignment of the $44.4 \mathrm{keV}$ transition is M1. Therefore we infer that the major mode of decay is a 271.9 (E3)-44.4 (M1) cascade, as indicated in the decay scheme given in fig. 6 .

Although the intensity of the $234 \mathrm{keV} \gamma$-ray is near the detection limit of the methods employed and a good half-life for this radiation could not be obtained, it appears likely that the assignment to ${ }^{134 \mathrm{~m}} \mathrm{I}$ is correct. It is not clear that the presence of this $\gamma$-ray implies direct $\beta$-feeding of the $7^{-}$level of ${ }^{134} \mathrm{Xe}$. The assignment of such 
a branch is based on the fact that no other $\gamma$-rays were detected, although any lowintensity $\gamma$-rays with energies below the Compton edge for the $272 \mathrm{keV} \gamma$-ray would not have been seen.

\subsection{CALCULATION OF INDEPENDENT FISSION YIELDS}

The intensity of the $\beta$-branch has a large effect on the apparent fission yield ratio of the ${ }^{134} \mathrm{I}$ isomers. The decay modes given in the decay scheme (fig. 6) imply that the activity of the $847 \mathrm{keV} \gamma$-ray at any given time contains contributions from decay

\begin{tabular}{rr}
$(1+)$ & 923.3 \\
\hline $1+1$ & 846.6 \\
\hline
\end{tabular}

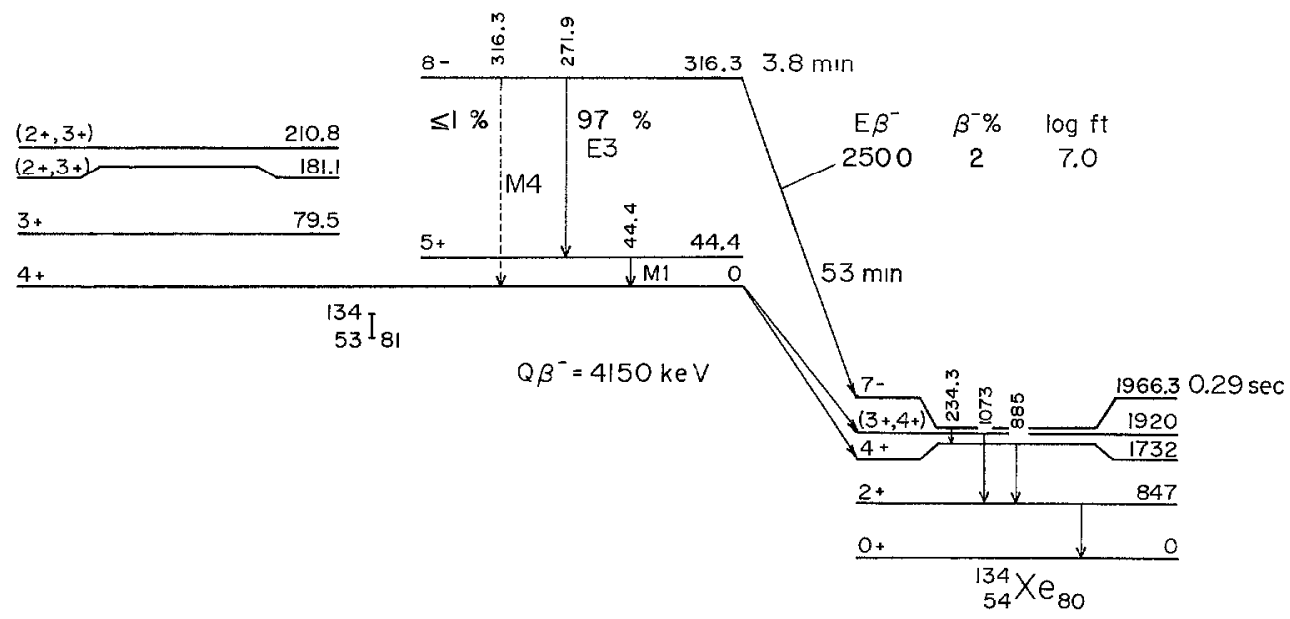

Fig. 6. Decay scheme of $3.8 \mathrm{~min}{ }^{134 \mathrm{~m}} \mathrm{I}$ and levels of ${ }^{134} \mathrm{I}$ observed in the $\beta$-decay of ${ }^{134} \mathrm{Te}$.

of ${ }^{134 \mathrm{~g} I}$ and from $\beta$-decay of ${ }^{134 \mathrm{~m}} \mathrm{I}$. Even if no ${ }^{134 \mathrm{~g}} \mathrm{I}$ were produced in fission $\left(\sigma_{\mathrm{m}} / \sigma_{\mathrm{g}}=\infty\right)$, the $847 \mathrm{keV} \gamma$-ray would show no growth if the $\beta$-branch were about $7 \%$. The activity of the $847 \mathrm{keV} \gamma$-ray is given by

$$
A_{\mathrm{T}}=\left[A_{\mathrm{g}}^{0}+\frac{\lambda_{\mathrm{g}}}{\lambda_{\mathrm{m}}-\lambda_{\mathrm{g}}} A_{\mathrm{m}}^{0}(1-f)\right] x_{\mathrm{g}} \mathrm{e}^{-\lambda_{\mathrm{g}} t}+\left[f x_{\mathrm{m}}-\frac{\lambda_{\mathrm{g}}}{\lambda_{\mathrm{m}}-\lambda_{\mathrm{g}}}(1-f) x_{\mathrm{g}}\right] A_{\mathrm{m}}^{0} \mathrm{e}^{-\lambda_{\mathrm{m}} t},
$$

where $A_{\mathrm{q}}^{0}=$ activity at $t=0$ coming from $53 \mathrm{~min}{ }^{134 \mathrm{~g}} \mathrm{I}$ decay, $A_{\mathrm{m}}^{0}=$ activity at $t=0$ coming from $3.8 \mathrm{~min}{ }^{134 \mathrm{~m}} \mathrm{I}$ decay, $\lambda_{\mathrm{g}}=$ decay constant of $53 \mathrm{~min}{ }^{134 \mathrm{~g}} \mathrm{I}, \lambda_{\mathrm{m}}=$ decay 
constant of $3.8 \mathrm{~min}{ }^{134 \mathrm{~m}} \mathrm{I}, x_{\mathrm{g}}=$ fraction of decays of $53 \mathrm{~min}^{134 \mathrm{~g}} \mathrm{I}$ giving rise to $847 \mathrm{keV}$ $\gamma$-ray, $x_{\mathrm{m}}=$ fraction of decays of $3.8 \mathrm{~min}^{134 \mathrm{~m}}$ I giving rise to $847 \mathrm{keV} \gamma$-ray, $f=$ fraction of the $3.8 \mathrm{~min}{ }^{134 \mathrm{~m}} \mathrm{I} \beta^{-}$decaying, $1-f=$ fraction of the $3.8 \mathrm{~min}^{134 \mathrm{~m}} \mathrm{I}$ decaying by IT.

From experimental values for the intensities of the 847 and $272 \mathrm{keV} \gamma$-rays, theoretical conversion coefficients ${ }^{19}$ ), the presumed decay schemes for ${ }^{134 \mathrm{~m} I}$ (fig. 6) and ${ }^{134 \mathrm{~g}} \mathrm{I}\left[\right.$ ref. $\left.{ }^{10}\right)$ ], the isomer ratio, $\sigma_{\mathrm{m}} / \sigma_{\mathrm{g}}$ is found to be $1.4 \pm 0.7$.

\section{Discussion}

The decay of ${ }^{134 \mathrm{~m}} \mathrm{Cs}$ is known ${ }^{20}$ ) to occur predominantly by a two-step cascade of $\gamma$-transitions. The spins and parities of the levels and the multipolarities of the transitions are the same as those inferred for ${ }^{134 \mathrm{~m}} \mathrm{I}$ in the present work. Therefore, it is of interest to compare the rates of the transitions observed in the decay of these two isomers. In addition to the data given in [ref. $\left.\left.{ }^{20}\right)\right]$, the half-life of the $11.2 \mathrm{keV}$ $5^{+}$level in ${ }^{134} \mathrm{Cs}$ has been determined by Lynch and Glendenin ${ }^{21}$ ), and the intensity of the $138.6 \mathrm{keV}$ crossover transition has been determined by Griffin ${ }^{22}$ ). The intensity of the $138.6 \mathrm{keV} \gamma$-ray is in agreement with the intensities of conversion electrons observed by Sunyar, Mihelich and Goldhaber ${ }^{23}$ ) and the assumption that the transition is M4. The data for ${ }^{134 \mathrm{~m}} \mathrm{Cs}$ and the extrapolations to ${ }^{134 \mathrm{~m}} \mathrm{I}$ are compared by Griffin ${ }^{22}$ ) and are consistent. The extrapolations were obtained by using the energy dependence for single-particle radiative transitions (e.g., $E_{\gamma}^{7}$ for $\mathrm{E} 3$ transitions) to correct for differences in transition energies; pure multipole transitions were assumed. From the comparison it is clear that the E 3 transitions are quite similar, and that the upper limit for the intensity of the M4 transition in ${ }^{134} \mathrm{I}$ is analogous to that in ${ }^{134} \mathrm{Cs}$.

The configurations of the $4^{+}$and $8^{-}$isomers of ${ }^{134} \mathrm{I}$ involve the odd $53 \mathrm{rd}$ proton lying either in the $g_{\frac{7}{2}}$ ground state or $d_{\frac{5}{2}}$ first excited state found at ${ }^{24}$ ) $312 \mathrm{keV}$ in ${ }^{133} \mathrm{I}$ and the single neutron hole ${ }^{25}$ ) lying either in the $\mathrm{d}_{\frac{3}{2}}$ ground state, $\mathrm{h}_{\frac{11}{2}}$ first excited state at $334.5 \mathrm{keV}$ or $\mathrm{s}_{\frac{1}{2}}$ second excited state at $423.5 \mathrm{keV}$ in ${ }^{133^{\prime}} \mathrm{T}$ 'e. The $5^{+}$state at $44 \mathrm{keV}$ can be constructed from only the $\left(\pi g_{\frac{7}{2}} \nu \mathrm{d}_{\frac{3}{2}}\right)_{5^{+}}$coupling whereas the $8^{-}$isomer can either be a $\left(\pi \mathrm{g}_{\frac{7}{2}} v \mathrm{~h}_{\frac{11}{2}}\right)_{8^{-}}$or $\left(\pi \mathrm{d}_{\frac{5}{2}} v \mathrm{~h}_{\frac{11}{2}}\right)_{8}$ - state and the $4^{+}$state can be $\left(\pi \mathrm{g}_{\frac{7}{2}} \nu \mathrm{d}_{\frac{3}{2}}\right)_{4^{+}},\left(\pi \mathrm{d}_{\frac{5}{2}} \nu \mathrm{d}_{\frac{3}{2}}\right)_{4^{+}}$, or $\left(\pi \mathrm{g}_{\frac{7}{2}} \nu \mathrm{s}_{\frac{1}{2}}\right)_{4^{+}}$. Because of the fixed configuration of the $5^{+}$intermediate state it may be seen that the $3.8 \mathrm{~min}$ IT represents effectively the M4 transition of the neutron from the $\mathrm{h}_{\frac{11}{2}}$ state to the $\mathrm{d}_{\frac{3}{2}}$ state. The $3.8 \mathrm{~min}$ half-life for this $\mathrm{E} 3$ transition may be compared with the $0.29 \mathrm{sec}$ half-life of the $234 \mathrm{keV}$ $\mathrm{E} 3$ transition in ${ }^{134} \mathrm{Xe}$. The transition in $\mathrm{I}$ is hindered by a factor of $\approx 2300$ relative to the transition in $\mathrm{Xe}$. On the other hand, the $3.8 \mathrm{~min}$ transition may be compared to the $334 \mathrm{keV} \mathrm{M} 4$ transition in ${ }^{133} \mathrm{Te}$ whose $\gamma$ de-excitation half-life is $\approx 440 \mathrm{~min}$ and an enhancement of only about $10^{3}$ found. These considerations support the above proposed configurations for the $4^{+}, 5^{+}$, and $8^{-}$levels in ${ }^{134}$ I. One configuration that can mix into the $8^{-}$state and lead to an E3 transition to the $5^{+}$state is $\left(\pi \mathrm{g}_{\frac{7}{2}} v \mathrm{~h}_{\frac{9}{2}}\right)_{8}$.. The $v \mathrm{~h}_{\frac{9}{2}}$ level lies $\left.{ }^{26,27}\right)$ above the $N=82$ closed shell and is $\approx 3 \mathrm{MeV}$ 
above the $h_{\frac{11}{2}}$ state. Only a small admixture of such a state is indicated or required to account for the observed half-lives.

If all of the intensity of the $234 \mathrm{keV} \gamma$-ray is assumed to arise from direct $\beta$-feeding of the $7^{-}$level in ${ }^{134} \mathrm{Xe}$, the $\log f t$ value of that transition is about 7 . This value is somewhat high for, but not inconsistent with, an allowed transition. From a microscopic point of view, however, $\beta$-decay of ${ }^{134} \mathrm{I}$ involves decay of the 81 st neutron to produce the 54 th proton, and direct $\beta$-decay to a two-neutron state ${ }^{16}$ ) is not expected.

Even though the intensity of the $\beta$-decay branch (or branches) of ${ }^{134 m} \mathrm{I}$ is not well known, it is clear that most of the decay leads to ${ }^{134 \mathrm{~g}} \mathrm{I}$. Therefore the existence of this isomer cannot explain the unexpected low fission yield ${ }^{13}$ ) of ${ }^{1348} \mathrm{I}$.

\section{References}

1) N. Sugarman, J. Chem. Phys, 17 (1949) 11

2) G.J. Perlow and A.F. Stehney, Phys. Rev. 113 (1959) 1269

3) N.R. Johnson and G.D. O'Kelley, Phys. Rev. 114 (1959) 279

4) H.O. Denschlag and A.A. Gordus, Zeit. anal. Chem. 226 (1967) 62

5) A. Lundan and A. Siivola, Ann. Acad. Scient. Fennicae A VI (1968) 287

6) M. McKeown and S. Katcoff, Phys. Rev. 94 (1954) 965

7) G. Holm and H. Ryde, Ark. Fys. 15 (1959) 387

8) N. R. Johnson, E. Eichler, G.D. O'Kelley, J. W. Chase and J.T. Wasson, Phys. Rev. 122 (1961) 1546

9) E. Takekoshi, H. Umezawa and T. Suzuki, Nucl. Phys. A133 (1969) 493

10) W.G. Winn and D.G. Sarantites, Phys. Rev. 184 (1969) 1188

11) H. N. Erten, C.D. Corycll and W.B. Walters, Bull. Am. Phys. Soc. 14 (1969) 1225

12) G. Holm, Ark. Fys. 37 (1968) 1

13) A. A. Delucchi, A. E. Greendale and P. O. Strom, Phys. Rev. 173 (1968) 1159

14) L. C. Carraz, J. Blachot, E. Monnand and A. Moussa, Compt. Rend. B 270 (1970) 358

15) H.N. Erten, C.D. Coryell and W.B. Walters, J. Inorg. Nucl. Chem. (1971), in press

16) W.G. Winn and D.C. Clark, Bull. Am. Phys. Soc. 11 (1966) 775; W.G. Winn, Ph. D. thesis, Comell Univ., Ithaca, N.Y. (1968), unpublished

17) J.P. Up de Beeck and W.B. Walters, J. Inorg. Nucl. Chem. 30 (1968) 228

18) G.W. Campbell and E.L. Brady, Radiochemical studies" the fission products, eds. C.D. Coryell and N. Sugarman (McGraw-Hill, New York,1951), paper 277, p. 1623

19) R.S. Hager and E.C. Seltzer, Nucl. Data 4 (1968) 1

20) C. M. Lederer, J. M. Hollander and I. Perlman, Table of isotopes, 6th ed., 1967

21) F.J. Lynch and L.E. Glendenin, Phys. Rev. 186 (1969) 1250

22) H.C. Griffin, to be published

23) A.W. Sunyar, J.W. Mihelich and N. Goldhaber, Phys. Rev. 95 (1954) 570

24) B. Parsa, G. E. Gordon and W. B. Walters, Nucl. Phys. A110 (1968) 674

25) H.N. Erten, C.D. Coryell and W.B. Walters, Nucl. Phys. March 1971, submitted

26) E.S. Macias and W.B. Walters, Nucl. Phys. A 169 (1971) 309

27) D. von Ehrenstein, G.C. Morrison, J.A. Nolen, Jr, and N. Williams, Phys. Rev. C1 (1970) 2066 